Hatgioannides, John; Karanassou, Marika; Sala, Hector

\title{
Working Paper \\ Should the rich be taxed more? The fiscal inequality coefficient
}

Working Paper, No. 832

\section{Provided in Cooperation with:}

School of Economics and Finance, Queen Mary, University of London

Suggested Citation: Hatgioannides, John; Karanassou, Marika; Sala, Hector (2017) : Should the rich be taxed more? The fiscal inequality coefficient, Working Paper, No. 832, Queen Mary University of London, School of Economics and Finance, London

This Version is available at:

http://hdl.handle.net/10419/184783

Standard-Nutzungsbedingungen:

Die Dokumente auf EconStor dürfen zu eigenen wissenschaftlichen Zwecken und zum Privatgebrauch gespeichert und kopiert werden.

Sie dürfen die Dokumente nicht für öffentliche oder kommerzielle Zwecke vervielfältigen, öffentlich ausstellen, öffentlich zugänglich machen, vertreiben oder anderweitig nutzen.

Sofern die Verfasser die Dokumente unter Open-Content-Lizenzen (insbesondere CC-Lizenzen) zur Verfügung gestellt haben sollten, gelten abweichend von diesen Nutzungsbedingungen die in der dort genannten Lizenz gewährten Nutzungsrechte.
Terms of use:

Documents in EconStor may be saved and copied for your personal and scholarly purposes.

You are not to copy documents for public or commercial purposes, to exhibit the documents publicly, to make them publicly available on the internet, or to distribute or otherwise use the documents in public.

If the documents have been made available under an Open Content Licence (especially Creative Commons Licences), you may exercise further usage rights as specified in the indicated licence. 


\title{
Should the Rich be Taxed More? The Fiscal Inequality Coefficient*
}

\author{
John Hatgioannides ${ }^{\dagger}$ \\ Cass Business School \\ City University, London
}

\author{
Marika Karanassou ${ }^{\dagger}$ \\ Queen Mary, University \\ of London and IZA, Bonn, Germany \\ Hector Sala ${ }^{\S}$
}

Universitat Autònoma

de Barcelona and IZA, Bonn, Germany

July 2017

\begin{abstract}
This paper holistically addresses the effective (relative) income tax contribution of a given income (or, wealth) group. The widely acclaimed standard in public policy is the absolute benefaction of a given income group in filling up the fiscal coffers. Instead, we focus on the ratio of the average income tax rate of an income group divided by the percentage of national income (or wealth) appropriated by the same income group. In turn, we develop the Fiscal Inequality Coefficient which compares the effective percentage income tax payments of pairs of income (or wealth) groups. Using data for the US, we concentrate on pairs such as the Bottom $90 \%$ versus Top 10\%, Bottom 99\% versus Top 1\%, and Bottom 99.9\% versus Top 0.1\%. We conclude that policy makers with a strong social conscience should re-evaluate the progressivity of the income tax system and make the richest echelons of the income and wealth distributions pay a fairer and higher tax.
\end{abstract}

JEL Classifications: H23, H30, E64

Keywords: Fiscal policy; progressive income taxation; inequality; effective income tax rate; fiscal inequality coefficient.

*Acknowledgments: Hector Sala is grateful to the Spanish Ministry of Economy and Competitiveness for financial support through grant ECO2016-75623-R.

${ }^{\dagger}$ Corresponding Author. Faculty of Finance, Cass Business School, City University, 106 Bunhill Row, London EC1Y 8TZ, UK; tel.: +44020 7040-8973; email: j.hatgioannides@city.ac.uk

${ }^{\ddagger}$ School of Economics and Finance, Queen Mary, University of London, Mile End Road, London E1 4NS, UK; tel.: +44 0207882 8822; email: m.karanassou@qmul.ac.uk

\$Departament d'Economia Aplicada, Universitat Autònoma de Barcelona, Edifici B, 08193 Bellaterra, Spain; tel: +34-93.581.27.79; email: hector.sala@uab.es. 


\section{Introduction}

Deep-seated and multi-facet challenges on the public finances of advanced economies make a convincing case to remould the debate for means-tested direct income tax hikes. ${ }^{1}$ Supplyside economics that has dominated policy since the beginning of the 1980s advocates deregulation, the weakening of welfare programmes and tax cuts. At the same time, the rich are hailed for their contribution in filling up the fiscal coffers. This is in line with textbook public economics which braces the argument that in a progressive income tax system, it is the top earners that support (through their income tax payments) the wider society significantly more than any other income group. True may be, but only in an absolute, dry, sense.

In this paper, we propose a holistic new index which re-evaluates the progressivity of the income tax system. ${ }^{2}$ Instead of focusing on merely the absolute income tax contribution, which is the standard practice, we rather concentrate on the ratio of the average income tax rate per given income group divided by the percentage of national income owned by the same income group. Our measure of the eflective (relative) income tax contribution is very flexible since in the denominator one can also use the percentage of the total household wealth appropriated by a reference income group.

Our numerical calculations are carried out for the US using the recent comprehensive distributional national accounts developed in Piketty, Saez and Zucman (2016). This unique and laborious dataset is a much needed tool to better monitor economic growth and its distribution. It is particularly pertinent for our work since our main objective is to profile our index further as the Fiscal Inequality Coefficient (FIC).

Once the ratio of the effective (relative) income tax contribution is calculated for each income group alone, the FIC (being free of units of measurement), allows easy comparisons of the actual benefaction into filling up the fiscal coffers of pairs of income (or wealth) groups. We mainly focus on the Bottom 90\% versus the Top 10\%, the Bottom 99\% versus the Top $1 \%$ and the Bottom $99.9 \%$ versus the Top $0.1 \% .3$ There is a voluminous literature in labour economics regarding the differential pay of skilled versus unskilled labour, the impact of new technologies, automation etc. To that end, we further report

\footnotetext{
${ }^{1}$ In the aftermath of the 2008-09 Great Recession, fiscal consolidation programmes are implemented in the rich economies, despite record low interest rate costs for servicing government debt issuance. Recent data from Thomson Reuters Datastream and the IMF show that the post-crisis fiscal tightening, defined as the change in structural government balance as percentage points (pp) of GDP between 2010 and 2016 , was for the G7 economies: US, 5.8pp; UK, 4.4pp; France, 3.6pp; Japan, 3.5pp; Germany, 3pp; Italy, 2.5pp; Canada, 2pp. At the same, the escallating costs of (i) health and social care; (ii) unemployment benefits and other fiscal transfers to the working poor due to the new landscape of automation; (iii) decreasing labour force participation; (iv) loss of manufacturing jobs; and (v) low-paid, precarious forms of employment, put a huge strain on a governments' balance sheet.

${ }^{2}$ The main theoretical ideas of this work have been previously introduced in Hatgioannides and Karanassou (2017a).

${ }^{3}$ Obviously, the FIC can be reported for any chosen pair of income (or wealth) groups.
} 
the FIC for the Top $10 \%$ against the Top $1 \%$, the Top $10 \%$ against the Top $0.1 \%$ and the Top 1\% against the Top 0.1\%; arguably, all highly-skilled income (or wealth) groups have benefited from the modern labour landscape.

Theoretically, the FIC ranges from the value of one (denoting perfect equality), to large values approaching, in the limit, infinity (perfect inequality). As such, it could potentially act as supplementary to the recognised benchmark for inequality, that is, the Gini coefficient which ranges from 0 (perfect equality), to 100 (perfect inequality).

The standard economic paradigm addresses the "holy trinity" of GDP growth, inflation and unemployment management. Still on the fringes of main macroeconomic theorizing and policy making, but recently receiving a great deal of attention and shaping the public debate, is the heavily skewed income/wealth distribution and the appropriation of the proceeds of growth by the top percentiles. We feel that inequality is the missing vital fourth statistic of economic well functioning.

For the last four decades, both the personal and functional income distributions have followed divergent paths in the US, see Figure 1 below as reported in Karanassou and Sala (2017). While increasing inequality in personal income distribution has been pushing the Gini coefficient relentlessly upwards, making the US look like more of a developing than an advanced country, the evolution in the functional distribution has been characterised by a downward trend in the labour income share. Since the labour income share can also be envisaged as the wage-productivity gap, its downward trend is a mere reflection of wages lagging further behind labour productivity, thus boosting the income of the capital holders.

Figure 1. Labour income share and income inequality in the US.

a. Absolute values.

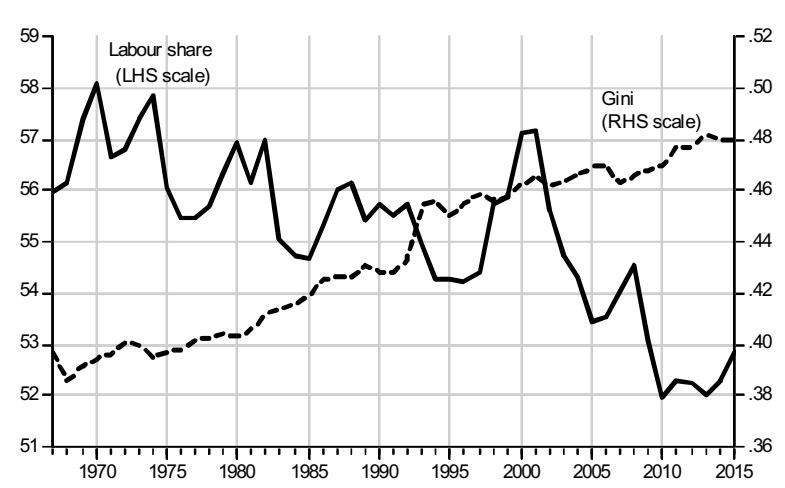

b. Index $100=1967$.

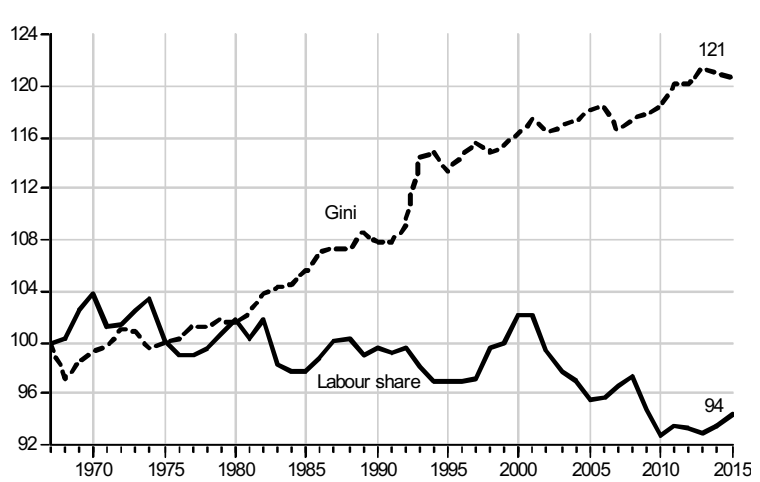

Note: all-worker nonfarm business sector labour share and income Gini ratio for households. Source: Karanassou and Sala (2017) based on data from the Bureau of Labor Statistics (BLS) for the labour share, and the US Census Bureau for the Gini index. 
It is self evident that income taxes configure the fiscal revenue space together with other direct/indirect taxes, insurance contributions and government borrowing. The FIC points to a much neglected, redistributive function that a trully progressive income (and wealth) tax should serve in a rich, albeit highly unequal, polarised and divided advanced economy such as the US.

The remainder of this paper is organised as follows. Section 2 offers a bird's eye view of why inequality is the missing fourth statistic of economic and social well being. Section 3 provides the workings for the calculation of the FIC and provides empirical evidence for the US. Finally, Section 4 concludes.

\section{Inequality: The Missing Fourth Statistic}

The renowned British historian Charles H. McIIwain (1932) noted that "...The idea of equality of men is the profoundest contribution of the Stoics to political thought...its greatest influence is in the changed conception of law that in part resulted from it" (pp. 114-115). In the same vein, the esteemed historian A.J. Carlyle (1903) wrote earlier "...There is no change in political theory so startling in its completeness as the change from the theory of Aristotle to the later philosophical view represented by Cicero and Seneca... We think that this cannot be better exemplified than with regard to the theory of the equality of human nature" (pp. 8-9).

Positivism in modern economics, nurturing an image of a value-free science in a valueladened discipline, is strenuously aiming to separate inequality from its philosophical, sociological and, most importantly, classical economics heritage. The topic of inequality was made largely irrelevant for influential parts of the mainstream, destined beyond the realm of micro founded, scientific economics. Lucas (2004) asserted that "Of the tendencies that are harmful to sound economics, the most seductive, and in my opinion the most poisonous, is to focus on questions of distribution".

Wisman and Smith (2011) thoroughly and critically review the (i) contributory, (ii) incentives, (iii) trickle-down, (iv) libertarian, and (v) fluid vertical mobility endeavors for legitimating inequality in economic and political theorising. They correctly, in our opinion, argue that "...such approaches to distributive justice have continually provided a powerful theoretical and political under-girding for those who oppose efforts to reduce inequality through policy. These approaches even favor policies that serve to increase inequality, such as tax cuts for the rich and cuts in public goods and social welfare for the poor" (pp. 995-996). ${ }^{4}$

\footnotetext{
${ }^{4}$ Wisman and Smith (2011) argue that (i) the marginal contributory argument insists that those who have more in our economy are typically those who contribute more, with the claim that is both natural and just; (ii) the incentives argument, strongly complements the contributory one, and suggests that inequality, or even more of it, is necessary for bringing forth behavior that contributes to economic
} 
Since the 1980s, the mainstay argument justifying inequality is the marginal contributory/incentives approach (see footnote 4 ). It is deeply entwined with the common intellectual roots of libertarian philosophy and neoclassical economics that set the autonomous individual at the center of the socioeconomic world.

Nozick (1974), perhaps the most influential proponent of libertarian justice, argued that a distribution of goods is just if brought about by free exchange from a just starting. point, even if large inequalities subsequently emerge from the process. He carried on, controversially arguing that a consistent upholding of the non-aggression principle would allow and regard as valid consensual or non-coercive enslavement contracts between adults in a typical "free system".

In a surprising reversal of his earlier philosophising, Nozick (1989) expressed, through his methodological ecumenism, serious misgivings about capitalist libertarianism, going so far as to reject much of the foundations of liberal theory on the grounds that personal freedom can sometimes only be fully actualised via "...a collectivist politics.... and that wealth is at times justly redistributed via taxation to protect the freedom of the many from the potential tyranny of an overly selfish and powerful few" (pp 71).

We are turning our attention next to justifying the redistributive function of taxation.

\section{The Fiscal Inequality Coefficient}

We proceed with the detailed calculations of the Effective Income Tax contribution and the FIC.

Assuming a uniform income distribution within a given income group, we define the Effective (relative) income tax contribution of a representative taxpayer in the income group as:

Average Income Tax Rate per Income group (\%)

Share of Total Pre-Tax Income of the Representative Taxpayer in the income group (\%)

If one further assumes that the $x$ percent of wealth-holders are the same people as the

dynamism; (iii) its trickle-down corollary claims that redistributing income to the rich who will save and invest it is best for everyone; (iv) the libertarian view asserts that policy measures to reduce inequality are more unjust than the inequality itself because the former involves the violation of individual rights and the latter does not; and (v) the fluid vertical mobility argument suggests that inequality is not an issue since everyone can by dint of dilligence make it to the top.

Wisman and Smith, ibid, articulate a forceful critique of all five aforementioned approaches to legitimating inequality by explaining in detail why they are grounded in theoretical constructs that distort social reality. 
$x$ percent of income holders, ${ }^{5}$ then a variant of expression (1) reads as:

Average Income Tax Rate per Income/Wealth group (\%)

Share of Total Houschold Wealth of the Representative Taxpayer in the Income/Wealth group (\%)

The FIC is then readily available if one divides expression (1) for pairs of income groups and/or expression (2) for pairs of wealth groups.

In reporting the FIC, we are typically using in the numerator the more populous income or wealth group. We are also employing the convention that the "Bottom $y$ percent group" of the income (wealth) distribution is the numerator of the FIC calculations whereas the "Top $(1-y)$ percent group" lies in the denominator (in the case that the income (wealth) brackets of a given pair add up to $100 \%$, or 1.00 of the income (wealth) distribution). ${ }^{6}$ It then follows that parity in the fiscal benefaction among income (wealth) groups is attained when the FIC is equal to one. Values of the FIC bigger than one produce unequal relative income tax contributions.

As an empirical illustration, we use the unique dataset for the US developed in Piketty et al. (2016). We adhere to the definition of the relevant variables provided therein. Figures 2 and 3 below plot the FIC based on income and household wealth shares, respectively, of the Bottom $90 \%$ versus the Top 10\%, the Bottom $99 \%$ versus the Top $1 \%$, and the Bottom 99.9\% versus the Top 0.1\% for 1962, 1980, 1995, 2010, and $2014 .^{7}$ Detailed calculations are provided in Table A1 in the Appendix.

\footnotetext{
${ }^{5}$ We acknoweledge that this is a very strong assumption with very debatable empirical validity. We are also aware that total personal wealth is made by both stock and flow variables. However, it is the income (flow) component of personal wealth that is routinely taxed more than the stock elements, hence our proxy calculations.

${ }^{6}$ It should be noted that in the calcualtion of the FIC, the pairs of the income or wealth brackets may not add up to $100 \%$ or the entire area of the distribution curve. (For example, Top 10\%/Top 1\%)

${ }^{7} A$ s explained in the note to Table $\Lambda 1$ in the $A$ ppendix, the selection of years for calculating the FIC is constrained by data availability in Piketty et al. (2016). Nevertheless, it may be considered as representative of different epochs that have signposted the trajectory of alternative economic policies: 60s (Year 1962) the Keynesian demand led/full employment era; 80s (Year 1980) the onslaught of the supply-side economics; 90s (Year1995) - the "roaring goldilock" economy. Year 2010 reflects the depths of the Great Recession and Year 2014 is representative of the straits of fiscal consolidation.
} 
Figure 2. Relative income tax contributions of the representative taxpayer: B90/T10; B99/T1; B99.9/T0.1

(FIC based on income shares)

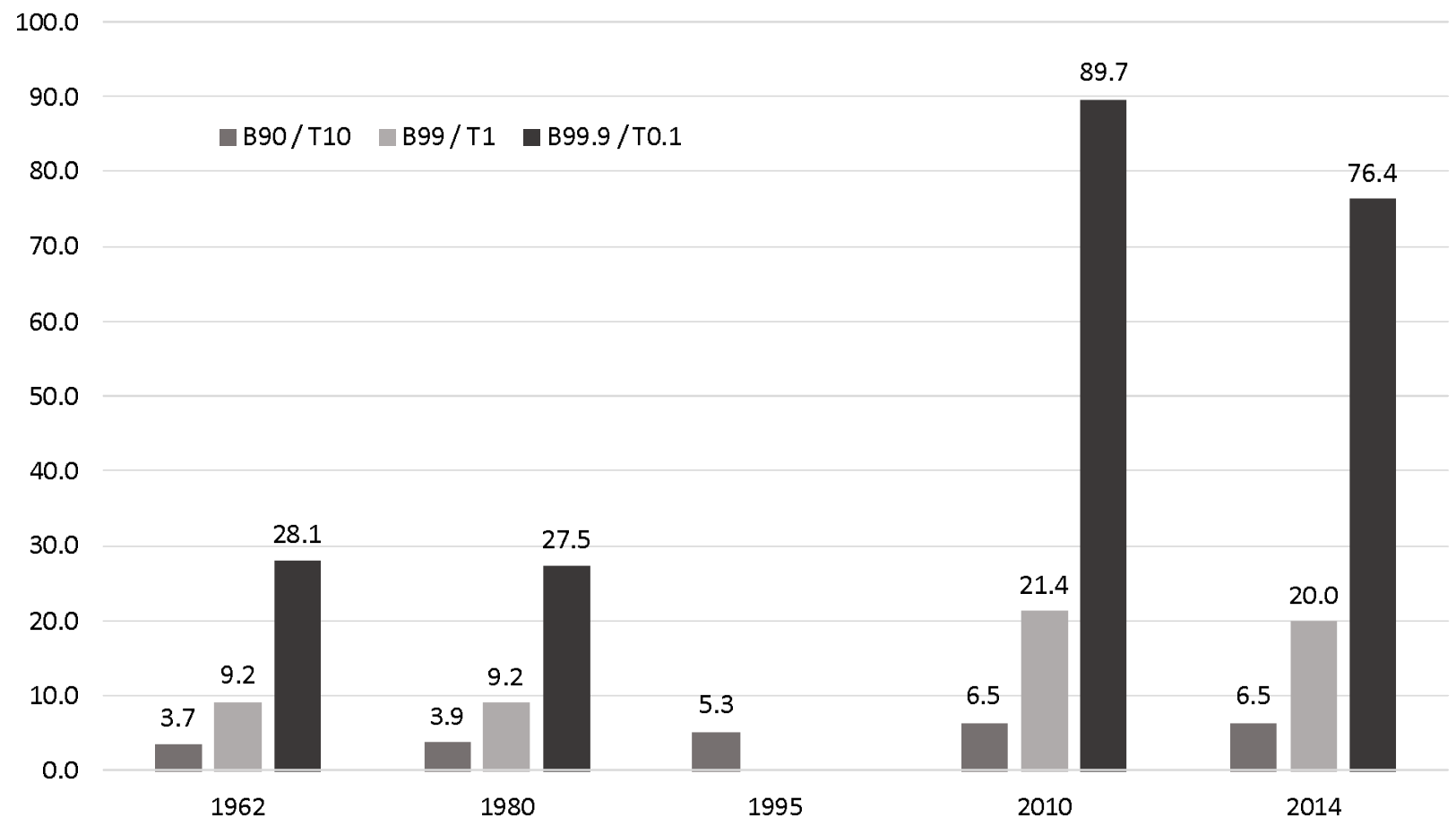

Note: see notes under Table A1.

Figure 3. Relative income tax contributions of the representative taxpayer: B90/T10; B99/T1; B99.9/T0.1

(FIC based on household wealth shares)

250.0

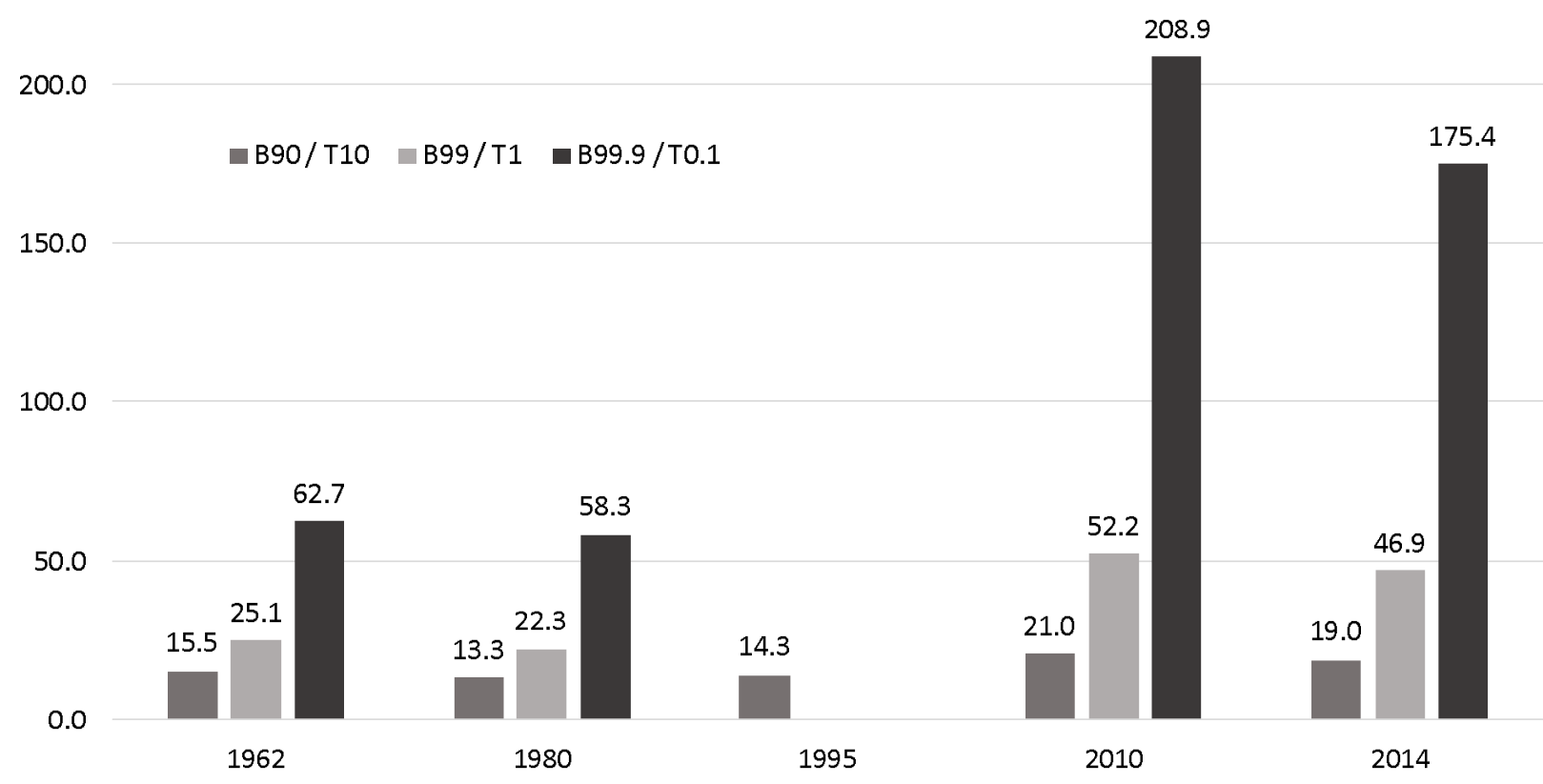

Note: see notes under Table A1. 
The results are starking. The FIC based on income shares remains relatively constant for all pairs for years 1962 and 1980 and increases significantly in year 2010, with the Bottom $99.9 \%$ effectively contributing 89.7 times more in the fiscal coflers than the Top $0.1 \%$; the aftermath of the Great Recession reduces the FIC to 76.4 for the same pair in 2014, still almost 3 times more than it was in 1980, the birth of supply-side economics.

The results are more eye-dropping if one calculates the FIC based on household wealth shares. However questionable our assumptions are in using wealth rather than income, it is very daunting to interpret the evidence that in the year 2010 the Bottom $99.9 \%$ contributed 208.9 times more than the Top $0.1 \%$, nearly four times over than in 1980 !

One should accept the premise that the top percentiles of the income and wealth distributions are populated by highly skilled individuals who are proficient to the new technologies. Figures 4 and 5 report the FIC based on income shares and household wealth shares for the Top $10 \%$ versus the Top $1 \%$, the Top $10 \%$ versus the Top $0.1 \%$ and the Top $1 \%$ versus the Top $0.1 \%$ for the same years as above. Once again, the detailed calculations may be found in Table A1 in the Appendix.

Figure 4. Relative income tax contributions of the representative taxpayer: T10/T1; T10/T0.1; T1/T0.1

(FIC based on income shares)

$$
25.0
$$$$
\square \text { T10/T1 } \square \text { T10/T0.1 } \square \text { T1/T0.1 }
$$

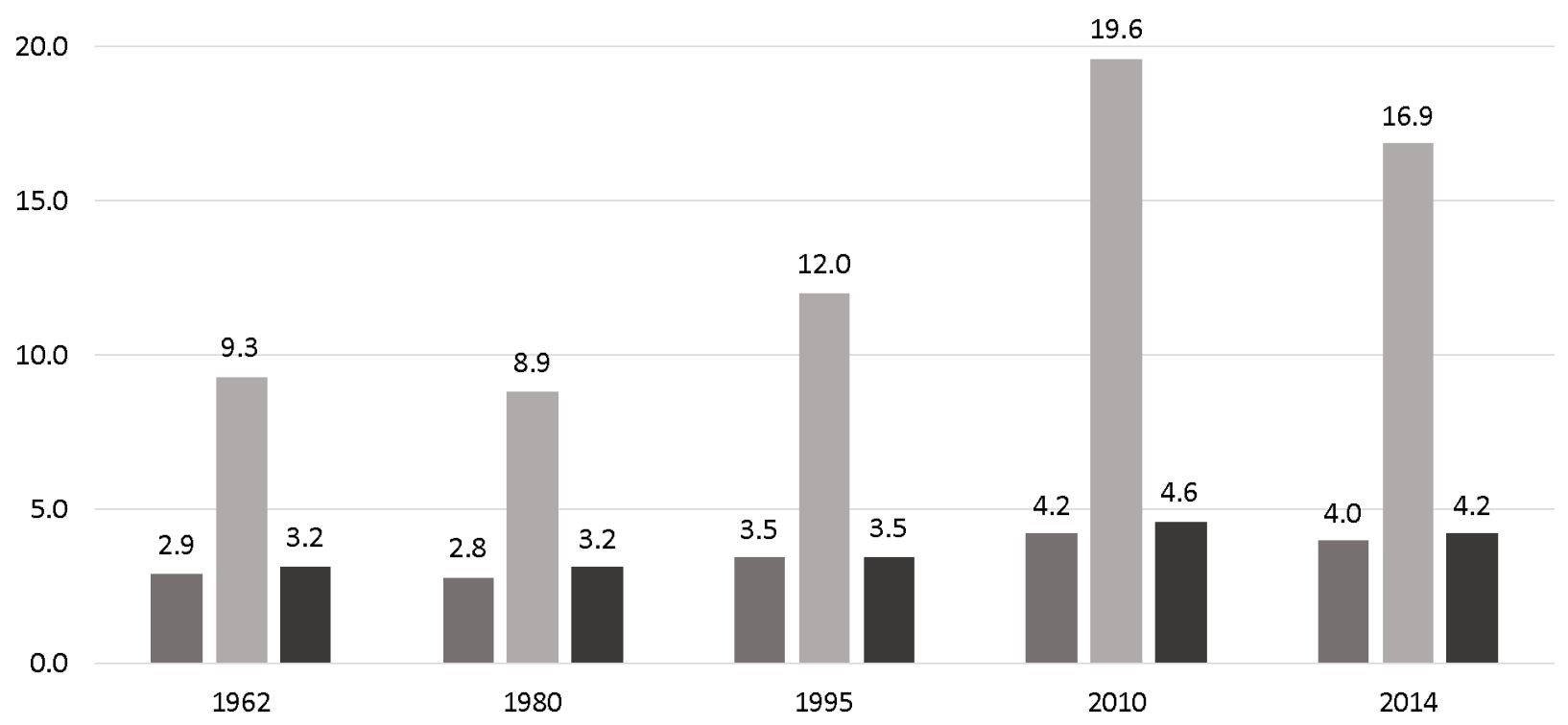

Note: see notes under Table A1. 
Figure 5. Relative income tax contributions of the representative taxpayer: T10/T1; T10/T0.1; T1/T0.1

(FIC based on household wealth shares)

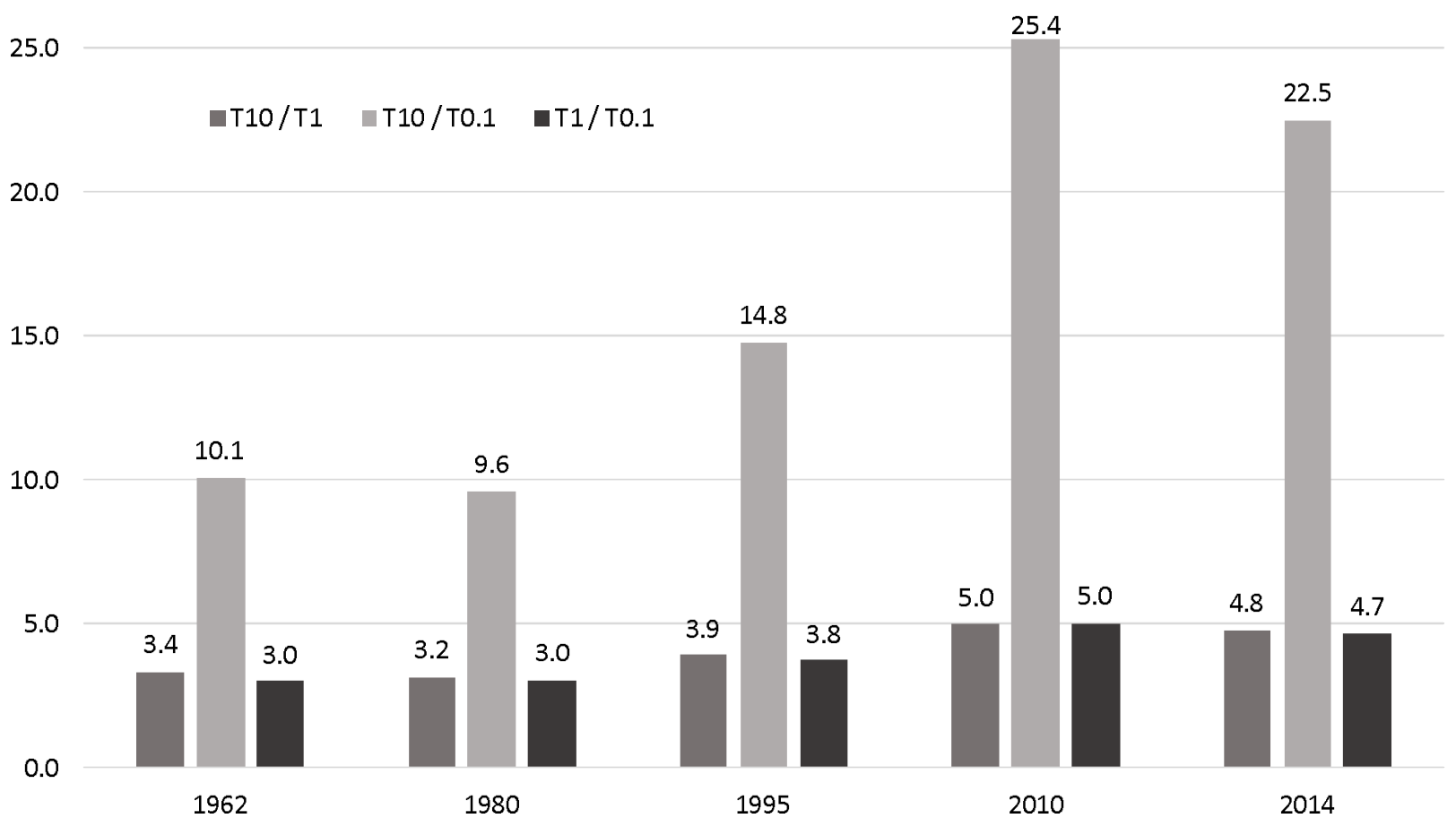

Note: see notes for Table A1.

Whereas the findings for the Top $10 \%$ versus the Top $1 \%$ and of the Top $1 \%$ versus the Top $0.1 \%$ do not differ much over the years and have comparable magnitudes, the Top $10 \%$ was effectively paying in the year 201019.6 times more than the Top $0.1 \%$ based on the income shares and 25.4 times more based on household wealth shares.

It is beyond the scope of this paper to provide an in-depth explanation of the systemic causes for the escallation of inequality in the advanced economies since the 1980s. We refer the interested reader to Hatgioannides and Karanassou (2017b).

\section{Conclusions}

In this paper we develop a flexible new measure called the Fiscal Inequality Coefficient (FIC) which compares the effective (relative) income tax contribution of different income and, under specific assumptions, wealth pairs of percentile groups. The FIC may be used in holistically assessing the progressivity of the direct income and can serve as a supplementary inequality index to the Gini coefficient.

Using the novel distributional national accounts for the US developed by Piketty et al. (2016), we calculate the FIC for three complementary pairs of income and wealth percentiles (Bottom $90 \%$ versus the Top 10\%, Bottom $99 \%$ versus the Top 1\% and Bottom 
$99.9 \%$ versus the Top $0.1 \%$ ) for a selection of years from the 1960 s up to the present. The FIC reaches its maximum value for all pairs in the midst of the Great Recession, the year 2010, having increased manifold since 1980, the year that supply-side economics took hold of economic policy in the US.

Using the iluminating lens of the FIC, we further examine as to whether there are significant differences between the evidently highly-skilled, familiar with the advent of new technologies, income and wealth pairs of the Top 10\% against the Top 1\%, Top 10\% against the Top $0.1 \%$ and Top $1 \%$ against the Top $0.1 \%$. Again, the highest values of the FIC are reported for the year 2010 with the pair of the Top $10 \%$ versus the Top $0.1 \%$ standing out in terms of unequal contribution into filling up the fiscal coffers.

The overarching policy question is the following: In the current era of fiscal consolidation should the rich be taxed more? Our evidence suggests unequivocally yes.

\section{References}

[1] Carlyle, A.J. (1903): A History of Medieval Political Theory in the West, Vol.1, Edinburgh and London: W. Blackwood and Sons.

[2] Hatgioannides, J., and M. Karanassou (2017a): "Do the Rich Actually Fill the Fiscal Coffers? Myths and Reality", Working Paper Series, Queen Mary, University of London, UK.

[3] Hatgioannides, J., and M. Karanassou (2017b): "Warrant Economics, Call-Put Policy Options and the Great Recession", Review of Political Economy, forthcoming.

[4] Karanassou, M., and H. Sala (2017): "Distributional Consequences of Capital Accumulation, Globalisation and Financialisation in the US", Unpublished manuscript [First version available as IZA Discussion Paper No. 7244, February 2013].

[5] Lucas, R.E. Jr. (2004): "The Industrial Revolution: Past and Future", Annual Report Essay, The Federal Reserve Bank of Minneapolis.

[6] Mcllwain, C.H. (1932): The Growth of Political Thought in the West: From the Greeks to the End of the Middle Ages, New York.

[7] Nozick, R. (1974): Anarchy, Stale, and Utopia, Basic Books, Inc.

[8] Nozick, R. (1989): The Examined Life, Simon \& Schuster, New York.

[9] Piketty, T., E. Saez, and G. Zucman (2016): "Distributional National Accounts: Methods and Estimates for the United States", NBER Working paper \#22945, Cambridge: Massachusetts.

[10] Wisman, J.D, and J.F. Smith (2011): "Legitimating Inequality: Fooling Most of the People All of the Time", The American Journal of Economics and Sociology, Vol.70, No. 4, pp. 974-1013. 
APPENDIX

Table A1. The Fiscal Inequality Coefficient. 1962, 1980, 1995, 2010, 2014.

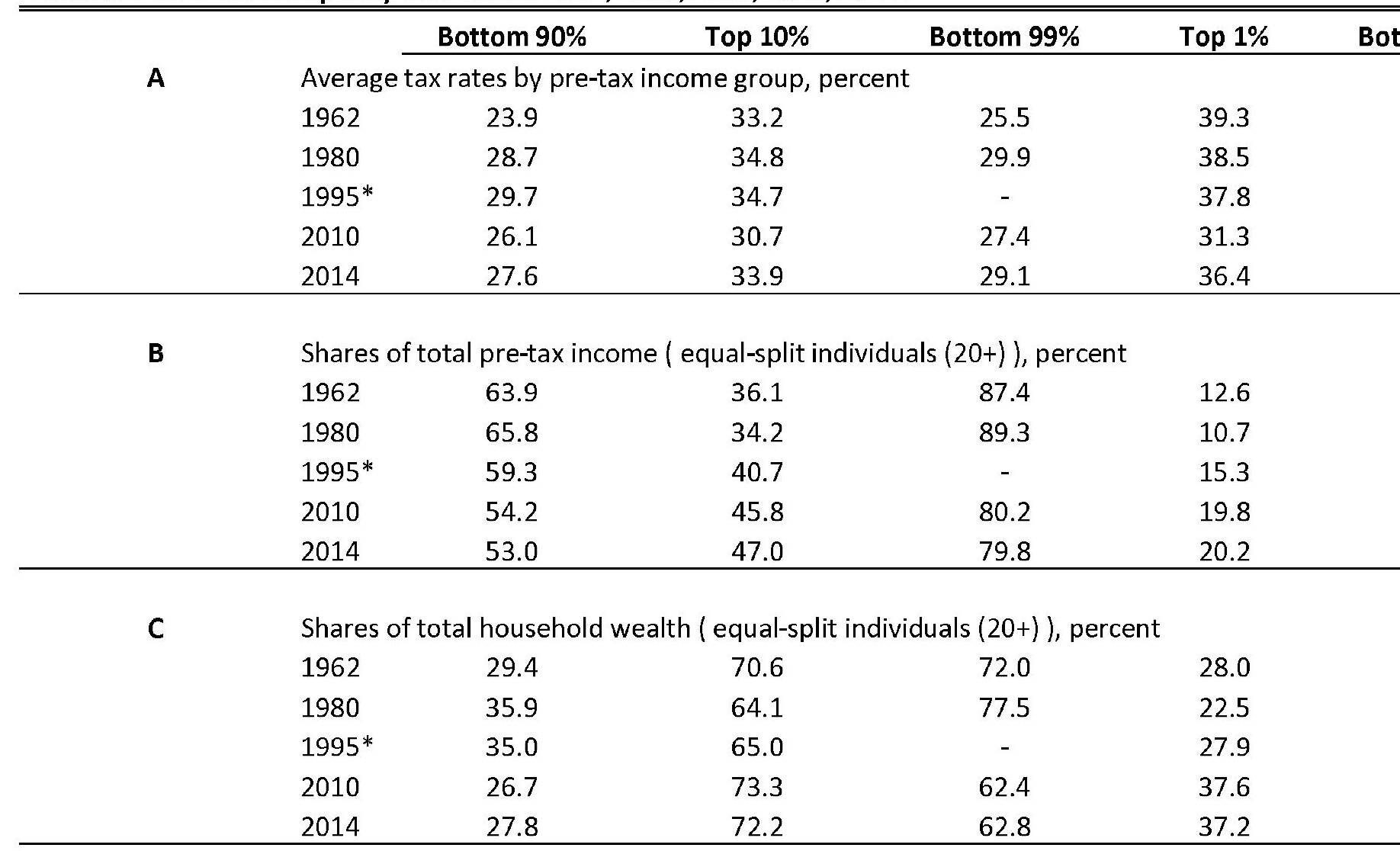




\begin{tabular}{|c|c|c|c|c|c|c|}
\hline & & Bottom 90\% & Top $10 \%$ & Bottom 99\% & Top $1 \%$ & Bottom 99 \\
\hline \multirow[t]{6}{*}{ D } & \multicolumn{6}{|c|}{ Number of adults $(20+)$} \\
\hline & 1962 & $102,373,597$ & $11,375,052$ & $112,611,147$ & $1,137,502$ & 113,634 \\
\hline & 1980 & $139,740,040$ & $15,526,767$ & $153,714,085$ & $1,552,722$ & 155,111 \\
\hline & $1995^{*}$ & $166,903,716$ & $18,544,857$ & - & $1,854,486$ & - \\
\hline & 2010 & $203,118,638$ & $22,569,569$ & $223,431,202$ & $2,257,005$ & 225,462 \\
\hline & 2014 & $210,996,660$ & $23,444,453$ & $232,096,606$ & $2,344,507$ & 234,206 , \\
\hline \multirow[t]{6}{*}{ B / D } & \multicolumn{6}{|c|}{ Denominator of the Fiscal Inequality Coefficient with the share of total pre-tax income } \\
\hline & 1962 & 0.0000006 & 0.0000032 & 0.0000008 & 0.0000110 & 0.00000 \\
\hline & 1980 & 0.0000005 & 0.0000022 & 0.0000006 & 0.0000069 & 0.00000 \\
\hline & $1995^{*}$ & 0.0000004 & 0.0000022 & - & 0.0000082 & - \\
\hline & 2010 & 0.0000003 & 0.0000020 & 0.0000004 & 0.0000088 & 0.00000 \\
\hline & 2014 & 0.0000003 & 0.0000020 & 0.0000003 & 0.0000086 & 0.00000 \\
\hline \multirow[t]{6}{*}{$C / D$} & \multicolumn{6}{|c|}{ Denominator of the Fiscal Inequality Coefficient with the share of total household wealth } \\
\hline & 1962 & 0.0000003 & 0.0000062 & 0.0000006 & 0.0000246 & 0.00000 \\
\hline & 1980 & 0.0000003 & 0.0000041 & 0.0000005 & 0.0000145 & 0.00000 \\
\hline & $1995^{*}$ & 0.0000002 & 0.0000035 & - & 0.0000151 & - \\
\hline & 2010 & 0.0000001 & 0.0000032 & 0.0000003 & 0.0000166 & 0.00000 \\
\hline & 2014 & 0.0000001 & 0.0000031 & 0.0000003 & 0.0000159 & 0.00000 \\
\hline \multirow[t]{6}{*}{$A /(B / D)$} & \multicolumn{6}{|c|}{ Fiscal Inequality Coefficient (over denominator with shares of pre-tax income) } \\
\hline & 1962 & $38,276,222$ & $10,458,486$ & $32,861,702$ & $3,556,011$ & 31,492, \\
\hline & 1980 & $61,014,499$ & $15,769,177$ & $51,379,086$ & $5,613,193$ & $48,919,2$ \\
\hline & $1995^{*}$ & $83,652,628$ & $15,830,471$ & - & $4,585,657$ & - \\
\hline & 2010 & $97,770,813$ & $15,128,519$ & $76,427,228$ & $3,566,718$ & $69,141,2$ \\
\hline & 2014 & $109,779,390$ & $16,931,378$ & $84,597,193$ & $4,228,461$ & $76,499,0$ \\
\hline
\end{tabular}




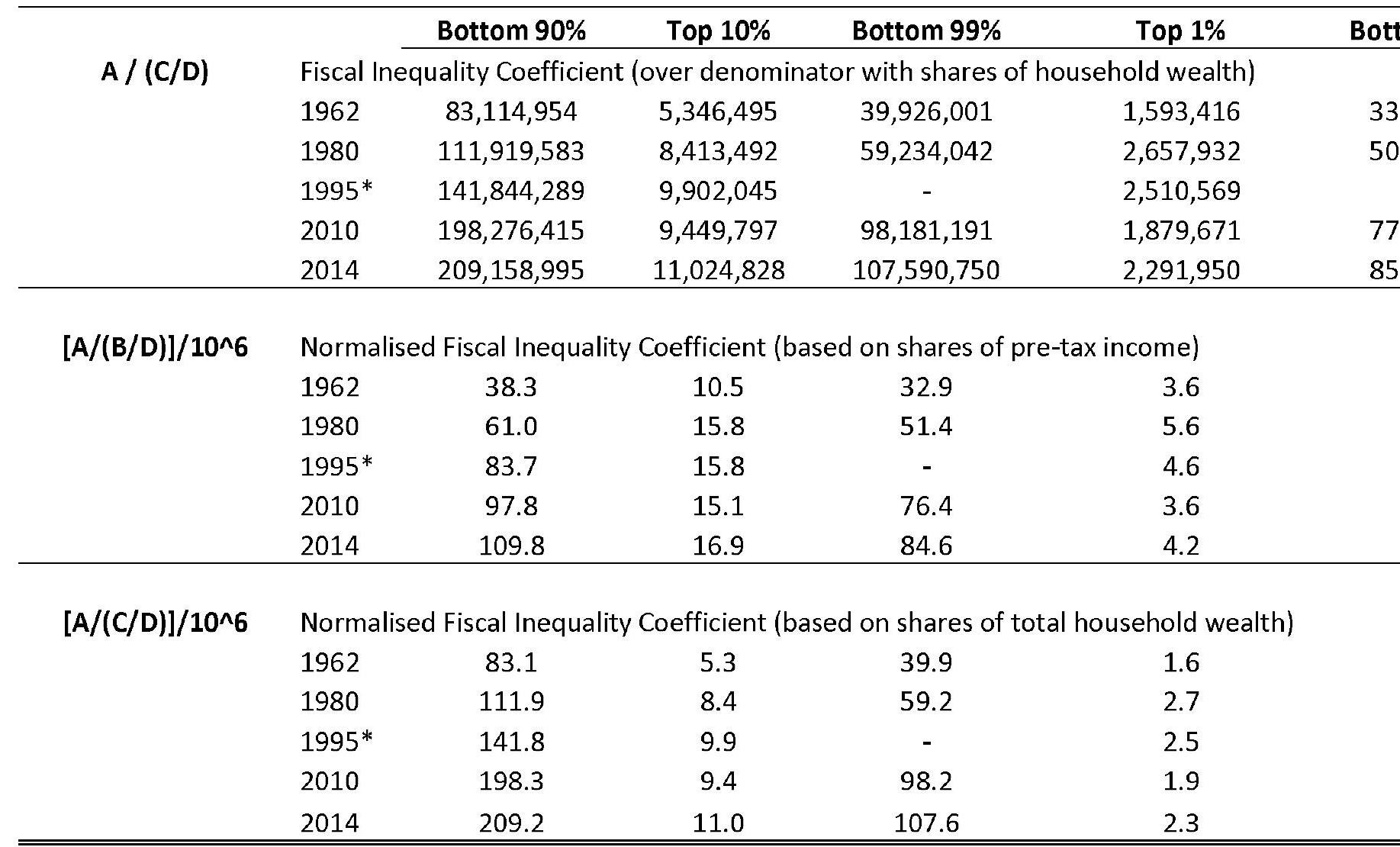

Note: Own calculations based on data from Piketty, Saez and Zucman (2016) and their reported statistics on the 0 income and total household wealth among equal-split adults in the US; the unit is the adult individual (20-year-olc couples is split into two).

$\left({ }^{*}\right)$ For 1995 , data on the number of adults $(20+)$ and the Bottom $99 \%$ and $99.9 \%$ shares is not given by Piketty number of adults as follows. We calculate the divergence (in \%) between the working-age population (source: $\mathrm{h}$ World Bank) and the number of adults (20+) in 1980 and 2010. We take the average divergence and apply it to 19 adult population for 1995. Based on this extrapolated population, we compute the FIC for 1995 for the Bottom $90 \%$ the Top $0.1 \%$ whose information for blocks A, B and C is available from Piketty et al. (2016). 


\title{
School of Economics and Finance
}

\author{
Q Queen Mary
}

University of London

This working paper has been produced by

the School of Economics and Finance at

Queen Mary University of London

Copyright @ 2017 John Hatgioannides, Marika Karanassou and Hector Sala all rights reserved

School of Economics and Finance

Queen Mary University of London

Mile End Road

London E1 4NS

Tel: +44 (0)20 78827356

Fax: +44 (0)20 89833580

Web: www.econ.qmul.ac.uk/research/workingpapers/ 